\title{
CONSIDERAÇÕES SEDIMENTOLÓGICAS E ESTRATIGRÁFICAS SOBRE A FORMAÇÃO CABO, PERNAMBUCO
}

\author{
MARGARETH MASCARENHAS ALHEIROS* MARIA DA GRAÇA DE VASCONCELOS XAVIER FERREIRA**
}

\begin{abstract}
SEDIMENTOLOGICALAND STRATIGRAPHICALCONSIDERATIONS REGARDING THE CABO FORMATION, PERNAMBUCO The Cabo Formation, consequence of the Aptian sedimentation during the rift phase in the Pernambuco-Paraíba Basin (Cabo Sub-basin), has been presented by new surface and subsurface data. Its importance in the regional context is greater than its restricted occurrence at surface might suggest. The formation does also appear on the adjacent continental shelf and chiefly on the submarine Pernambuco Plateau, where it occurs below limestones correlated with the Estiva Formation, and separated by a sharp unconformity. Sedimentologically the Cabo Formation is composed of syntectonic conglomerates and arkoses which form coalescent alluvial fans advancing into an apparently restricted tectonic lake. Upon these fans a braided fluvial system, poorly developed, was established, built up under high to moderate energy flows. Based upon subsurface samples the Cabo Formation has been dated as Aptian (Late Alagoas) and the Estiva Formation as Late Cenomanian to Early Turonian.
\end{abstract}

\begin{abstract}
RESUMO A Formação Cabo, registro da sedimentação aptiana durante a fase rifte na porção sul da Bacia Pernambuco - Parába (Sub-Bacia Cabo), tem se mostrado, à luz de novos dados de superfície e subsuperfície, bem mais importante no contexto regional do que sugere sua restrita ocorrência em superfície. Essa formação preenche grabens relativamente profundos (mais de 3.000 metros na praia de Cupe), que se estendem pela plataforma continental até o Platô de Pernambuco, subjacente a calcários correlacionáveis à Formação Estiva, separada desta por marcante discordância regional. Sedimentologicamente, a Formação Cabo é constituída por conglomerados e arcósios sintectônicos que formam leques aluviais coalescentes progradando para um lago tectônico aparentemente restrito. Em alguns pontos, desenvolve-se um sistema fluvial entrelaçado sobre esses leques sob condiçóes de alta a moderada energia. Dados paleontológicos obtidos em amostras de subsuperfície permitem situar as Formaçóes Cabo e Estiva, respectivamente no Aptiano (Alagoas) e no Cenomaniano Superior/Turoniano Inferior.
\end{abstract}

INTRODUÇÃO A Sub-Bacia Cabo corresponde ao extremo meridional da Bacia Pernambuco-Paraíba, estruturalmente limitada pelo alto de Maragogi e o Lineamento Pernambuco. Amplamente encoberta por sedimentos cenozóicos, as rochas cretáceas que a preenchem afloram segundo uma estreita faixa praticamente contínua, de direção N-S, entre os paralelos $8^{\circ} 06^{\prime}$ e $8^{\circ} 50^{\prime}$ de latitude sul (Fig. 1), que tem sido alvo de estudos sob diferentes abordagens.

No entanto, apesar da significativa produção de trabalhos sobre a área (um a cada 2, 3 anos entre 1960 e 1983), persistiu uma embaraçosa dificuldade no campo para a distinção entre sedimentos do Grupo Barreiras, que não sejam tipicamente "Guararapes", e os da Formação Cabo, que não sejam tipicamente "Conglomerado Cabo", além de alguns afloramentos do próprio embasamento cristalino granítico,

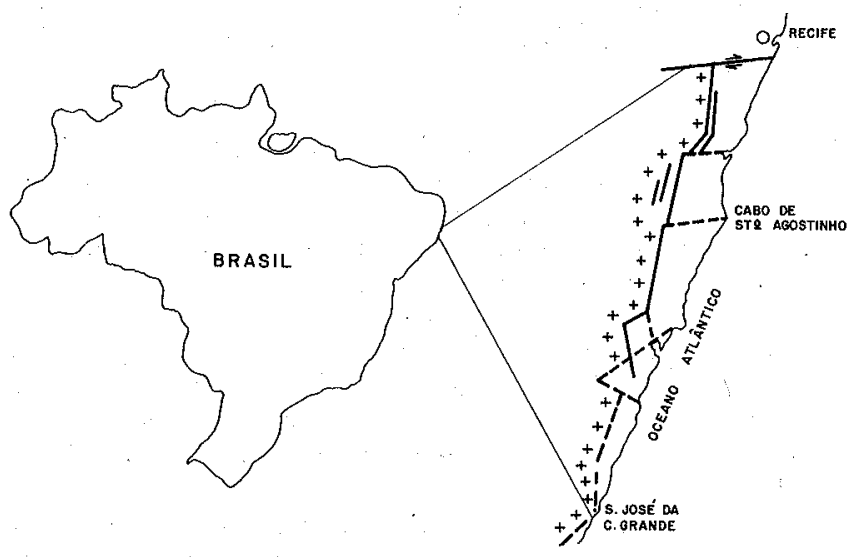

Figura 1-Mapa de situação

Figure 1 -Situation map nos quais a esfoliação esferoidal gera, atualmente, blocos arredondados do mesmo porte daqueles que constituem o conglomerado. Além disso, os derrames vulcânicos, quando alterados, produzem camadas argilosas de coloração avermelhada que podem ser confundidas tanto com os sedimentos do Grupo Barreiras como com as camadas argilosas da Formação Cabo.

Essa indefiniçẫo conduziu a mapeamentos localmente conflitantes no que se refere à litologia, sendo lembrada por Rand, em sua tese de livre-docência apresentada à UFPE em 1976, a necessidade de se proceder a uma caracterização sedimentológica mais segura tanto dos sedimentos do Grupo Barreiras como dos da Formação Cabo.

Nesse sentido, está em desenvolvimento um projeto mais amplo com vistas à caracterização sedimentológica das diversas unidades sedimentares da Bacia Pernambuco-Paraíba e do seu contex to estrutural. Esse trabalho apresenta parte dos resultados obtidos sobre a Formação Cabo a partir de estudos de laboratório (petrografia, difratometria, paleontologia etc.) e de campo. Tem como ênfase a definição dos sistemas deposicionais e dos processos sedimentológicos envolvidos, e a discussão do posicionamento estratigráfico dessa formação.

EVOLUÇÃO DOS CONHECIMENTOS Mais de meio século se passou desde os primeiros registros da ocorrência de sedimentos, hoje comprovadamente cretáceos, na faixa costeira sul de Pernambuco.

Entretanto, foi a partir dos trabalhos de Kegel, em 1959, e de Cobra, em 1960, que esse material veio a ser estudado mais detalhadamente, estando hoje caracterizado como um pacote clástico constituído por conglomerados, arcósios e camadas síltico-argilosas (Formação Cabo) e algumas ocorrências isoladas de calcários, de correlação aịnda duvidosa (Formação Estiva).

A Formação Cabo já foi posicionada sobre e sob a

* Departamento de Geologia da UFPE, Centro de Ténologia. Rua Acadêmico Hélio Ramos s/nº, 6 andar, Cidade Universitária, CEP 50741, Recife, PE, Brasil

** Departamento de Agronomia da UFRPE. Rua Dom Manoel Medeiros, s/nº, Dois Irmãos, CEP 52071, Recife, PE, Brasil 
Formação Estiva e um provável sincronismo também já foi sugerido, colocando-as como registros simultâneos da sedimentação cretácea na área.

Questionamentos sobre a gênese e a posição estratigráfica dessas unidades passaram a ser então temas enfocados nos trabalhos posteriores nos quais ora se retomava a origem coluvial, de Kegel, ora a tectônica, de Cobra, acrescendo-se cada vez mais de dados geocronológicos provenientes da identificação de novos fosséis encontrados, ou de datações radiométricas nas rochas vulcânicas associadas.

Oliveira \& Leonardos (1943) fazem as primeiras referências sobre conglomerados na região de Cabo, aos quais atribuem idade terciária, posicionando-os como um andar da "Série das Barreiras" (sic), denominação também proposta pelos autores.

Iniciando a discussão sobre a gênese do pacote conglomerático que denominou "Conglomerado de Cabo", Kegel (1959) atribui sua deposição a torrentes ao pé de uma escarpa, sob clima árido. Define como improvável uma idade pré-devoniana e indica o Eoterciário como limite temporal superior.

Cobra (1960) definiu esse pacote clástico como sendo uma formação complexa constituída pelas fácies brechóide, conglomerática e arcosiana, ao qual denominou "Formação Cabọ", cuja origem estaria ligada à reativação de antigas falhas longitudinais à costa. Atribuiu idade neocretácea a eoterciária para a Formação Cabo e albiana, para a Formação Estiva.

Discordando da idéia de um caráter sintectônico desses conglomerados, Andrade \& Lins (1961) atribuíram sua origem à acumulação coluvial de grande quantidade de blocos gerados por intensa esfoliação esferoidal subaérea em falésias vivas do embasamento cristalino. Denominados pelos autores "Conglomerado do Baixo Pirapama", fariam parte do "glacis" de detritos de idade cenozóica formado pelos sedimentos Barreiras.

Bigarella \& Andrade (1964) também creditaram a origem da Formação Cabo a processos morfoclimáticos, em ambiente continental de clima árido. Com base nas observações de campo, sugerem idade pós-cretácea para a referida unidade.

$O$ posicionamento estratigráfico da Formação Cabo pôde ser mais bem definido quando Vandoros \& Valarelli (1976) determinaram idades entre 87 e $114 \mathrm{Ma}$ para rochas vulcânicas que cortam e/ou recobrem os sedimentos da Formação Cabo. Assim, estes não poderiam ter idade pós-turoniana, ficando descartada sua correlação com depósitos cenozóicos. Permanece indefinido, no entanto, seu limite temporal inferior.

Pedrosa Jr. (1969) descreveu como pertencente à Formação Cabo uma seqüência rítmica de arcósios conglomeráticos e argilitos, acumulada sobre conglomerados que ocorrem a norte de Serinhaém (PE), introduzindo assim um componente pelítico ao material rudáceo já conhecido.

Mabesoone (1971), com base em análises granulométricas, atribui $o$ arredondamento dos blocos do conglomerado a processos sedimentológicos ao pé de escarpas de falhas e inclui os calcários Estiva como parte da Formação Cabo. Falcão (1976) corrobora essas idéias e conclui que $2 / 3$ dos blocos foram arredondados por transporte fluvial e $1 / 3$, em ambiente praial, também com base na granulometria.

Rand (1976), tendo por base estudos geofísicos realizados na Bacia Pernambuco-Paraíba, identifica uma tectônica de falhamento em blocos com escalonamento para leste e o conseqüente preenchimento pelos sedimentos da Formação Cabo. Também constata a continuidade, em subsuperfície, das formaçóes Cabo e Estiva por toda a sub-bacia sul até a Bacia Sergipe-Alagoas, definindo o comportamento sísmico dessas unidades.

O tectonismo e a subseqüente sedimentação na faixa costeira Pernambuco-Paraíba têm sido comumente tratados no contexto mais amplo da Margem Continental Brasileira em escalas que a tornam pouco representativa. Numa análise mais aproximada, Asmus \& Carvalho (1978) identificam a Formação Cabo com a sedimentação eo-cretácea da fase rifte e o calcário Estiva, com a transgressão albiana bem representada nas bacias costeiras. A não-deposição na Bacia Pernambuco-Paraíba do intervalo evaporítico encontrado na área de Sergipe é atribuída à posição estruturalmente mais elevada dos blocos a norte da Fratura de Maceió.

Uma tentativa de definição do comportamento faciológico da Formação Cabo foi apresentada por Amaral \& Menor (1979) a partir de descrições litológicas de sondagens de limitada profundidade na área do Projeto Suape. Identificaram três seçôes: uma inferior (Neocomiano-Aptiano), continental, onde os conglomerados e arcósios representariam leques de piemonte passando a fluvial anastomosado e os pelitos, um regime fluvial meandrante até estuarino; uma intemediária (Neocomiano-Albiano) associada a sulfetos onde se intercalam sedimentos carbonáticos de um primeiro ciclo transgressivo; e uma superior (Albiano-Turoniano), onde são registrados o segundo ciclo transgressivo argilo-carbonático de caráter transicional e o terceiro ciclo transgressivo, francamente marinho, constituído pelos calcários Estiva.

Em material amostrado nessas mesmas sondagens, Laurindo (1983) distinguiu duas microfácies compostas (doloesparito argiloso e argilito sítico) incluindo-as na Formação Cabo. Correlacionou-as ao Membro Ibura da Formação Muribeca, admitindo que, no Aptiano, a área de Suape pertencia ao conjunto estrutural da Bacia Sergipe-Alagoas.

Alves \& Costa (1986) comparam a seqüência identificada no Platô de Pernambuco com a Bacia Pernambuco-Paraíba e interpretam o pacote basal do Platô (Unidade I) como sendo clásticos da fase rifte. Com base em marcante discordância erosiva atribuída ao final do Aptiano, delimitam a idade dessa unidade como sendo Neocomiano a Aptiano e a correlacionam com a Formação Cabo no continente.

CARACTERIZAÇÃO SEDIMENTOLÓGICA Como parte dessa caracterização procedeu-se a uma definição litológica mais precisa das unidades que compõem a Formação Cabo pelo estudo sistemático de seções delgadas de blocos do conglomerado, de sua matriz e dos arcósios; os argilitos foram analisados por difratometria de raios $\mathrm{X}$.

Para a caracterização sedimentológica propriamente dita, foi feito o estudo detalhado de campo, no intuito de coletar o maior número possível de informações acerca da geometria dos corpos sedimentares, das características texturais e das estruturas sedimentares, como base para a definição das fácies e sistemas deposicionais.

Litologia OS CONGLOMERADOS Os conglomerados da Formação Cabo são polimodais, polimíticos (granitos finos e grossos, migmatitos, gnaisses, raros micaxistos grossos), com blocos bem arredondados de diâmetros variando de poucos centímetros até quase $2 \mathrm{~m}$ em uma matriz fragmentar escassa de composiçāo arcosiana.

Em escala microscópica, observa-se a existência de uma "matriz da matriz", constituída por material pelítico e palhetas de micas de dimensão inferior a 30 mícrons, que foi denominada pseudomatriz filossilicática, para distingui-la da observada em escala macroscópica.

Tanto os blocos quanto a matriz apresentam uma composição típica de rochas graníticas em que a microclina, apesar de alterada, apresenta-se em geral bem formada com geminação polissintética cruzada bem definida, indicando provir de rochas bastante granitizadas; o quartzo é policristalino e mostra-se com aspecto límpido enquanto as biotitas apresentam-se desferrificadas e expandidas em leques, indicando intensa hidratação; ocorrem ainda moscovita, 
zircão, hornblenda e opacos em pequena quantidade. Os plagioclásios são raramente identificados e podem constituir parte dos grãos irreconhecíveis em avançado estágio de argilização e que vão sendo incorporados à pseudomatriz filossilicática. Esta, por sua vez, mostra argilas associadas a lamelas e feixes de fibras de sericita e hidromica (illita); intensamente impregnadas por óxido de ferro. Com base em Folk (1974), a matriz do conglomerado foi classificada como arcósio imaturo ferriffero.

$\mathrm{O}$ estudo petrográfico mostrou que o arcabouço e a matriz do conglomerado são composicionalmente muito semelhantes, porém guardam significativa diferença no que se refere aos aspectos texturais: enquanto os blocos de diferentes calibres são bem arredondados e com alta esfericidade, a matriz é fragmentar angulosa e imatura. A semelhança composicional indica uma mesma fonte para blocos e matriz e o caráter imaturo desta última demonstra um curtíssimo transporte, insuficiente para $o$ arredondamento do arcabouço.

No entanto, Mabesoone (1971) atribuiu o arredondamento dos blocos do conglomerado a processos sedimentológicos em ambiente litorâneo escarpado, admitindo processos de alta energia que permitissem o arredondamento de blocos de até quase $2 \mathrm{~m}$ de diâmetro.

A hipótese de uma intensa esfoliação esferoidal como responsável pelo arredondamento desses blocos foi defendida por Kegel (1959), Andrade \& Lins (1961) e Bigarella \& Andrade (1964), o que encontra suporte nas observaçōes de campo. Essa forma de intemperismo químico é claramente observada tanto em rochas graníticas do embasamento cristalino como nas rochas vulcânicas e prossegue nos próprios blocos que constituem o conglomerado (Foto 1).

Do ponto de vista diagenético, a matriz apresenta evidências de pouco ou nenhum soterramento nas amostras de superfície, indicando um estágio redoxomórfico (eodiagenético), com forte influência pedogenética. No entanto, em amostras de subsuperfície ainda não estudadas em detalhe, observa-se crescente cimentação carbonática com a profundidade.

\section{OS ARCÓSIOS Esta rocha, bem exposta em superfície,} apresenta aparente uniformidade granulométrica, o que the confere um aspecto isotrópico lembrando a textura de um granito fino. Esparsos nessa massa ocorrem blocos de rochas graníticas muito bem arredondados, com diâmetro máximo de $15 \mathrm{~cm}$ em avançado estágio de decomposição.

Sua composição mineralógica é muito semelhante à da matriz do conglomerado, diferindo desta por apresentar, em amostras de superfície, uma cimentação carbonática significativa - com freqüentes romboedros de dolomita - e uma menor participação da pseudomatriz filossilicática, tendo sido classificado como arcósio calcítico imaturo, com seixos.

Apesar das evidências de soterramento pouco profundo, a cimentação carbonática parcial permite admitir uma etapa um pouco mais avançada do processo diagenético (locomórfico inicial), porém ainda no campo da eodiagênese.

Ocorrem ainda sob a forma de camadas de até $1 \mathrm{~m}$ de espessura, intercaladas em argilitos, arcósios conglomeráticos com aspecto fragmentar de composição semelhante aos anteriores, em que os elementos acima de $2 \mathrm{~mm}$ são angulosos fragmentos de mesma natureza que sua matriz arenosa grossa, tendo sido classificados como arcósio conglomerático imaturo ferrifero.

OS ARGILITOS Ocorrem sob a forma de camadas pouco pouco espessas intercalados aos arcósios conglomeráticos e apresentam cor marrom-avermelhada e verde. Quebram-se em formas tabulares, segundo níveis onde se verifica uma maior concentração de micas finas, o que lhes confere um brilho sedoso.
Por difração de raios $\mathrm{X}$, foram identificados na fração argila a esmectita, a caulinita, a mica e interestratificados; essa mineralogia é perfeitamente compatível com a das outras frações.

Fácies e sistemas deposicionais A Formação Cabo aflora segundo uma faixa estreita (de 2 a $3 \mathrm{~km}$ ) e alongada (65 $\mathrm{km}$ ), aproximadamente paralela à linha de costa, de modo praticamente contínuo, entre os munícipios de Ponte dos Carvalhos (PE) 'e Barreiros (PE), tendo como limite meridional a margem norte do Rio Una. O reconhecimento das fácies ambientais e dos processos sedimentológicos que lhes deram origem é assim dificultado, tendo em vista que se dispôs essencialmente de dados de superfície. Desse modo, a extensa cobertura de cana-de-açúcar associada ao intenso intemperismo químico e o relevo rebaixado com ampla cobertura aluvial somam-se às dificuldades encontradas para um mapeamento faciológico mais preciso (Fig. 2).

A atividade tectônica intermitente, por interromper o processo de construção sedimentológica do sistema deposicional, complicou sobremaneira a geometria dos corpos sedimentares.

SISTEMA DE LEQUES ALUVIAIS Bem exposto nas porções mais a norte e a sul da área estudada, ocorre bordejando linhas de falhas de gravidade representado por conglomerados, arcósios e argilitos micáceos nos quais se distinguem as fácies proximal, mediana e distal.

A fácies proximal ou supraleque, que corresponde à parte apical das cunhas clásticas, é encontrada na porção norte dä área, ocupando as topografias mais elevadas do lado sedimentar incluindo o morro onde está implantada a cidade do Cabo, associada a falhas normais de direção aproximada $\mathrm{N} 10^{\circ} \mathrm{E}$.

É constituída por conglomerados polimíticos grossos e desorganizados, com blocos de granulometria muito variada, de seixos a matacões, praticamente desprovidos de matriz (Foto 2), depositados a partir de fluxos de detritos.

Apesar da proximidade da área-fonte, este fanglomerado mostra blocos bem arredondados pela intensa esfoliação esferoidal. Nos extensos cortes a sul da cidade de Cabo, apresenta espessuras superiores a $60 \mathrm{~m}$.

São comuns acumulações descontínuas de arcósios com espessuras não superiores a $1 \mathrm{~m}$, intercalados nesses conglomerados, resultantes de enxurradas esporádicas espraiadas, as quais organizam de modo incipiente os blocos que se situam imediatamente abaixo.

$\mathrm{Na}$ fácies de leque mediano, o conglomerado apresenta uma estrutura mais organizada, em que seixos mais alongados se orientam com os maiores eixos na horizontal e ligeira imbricação, indicando movimento do agente transportador de W para $\mathrm{E}$, e foi depositado por processos de torrentes em lençol, em regime de fluxo de alta energia, localmente acanaladas.

Sobre esses conglomerados instalam-se canais preenchidos por arcósios portando pequếnos blocos de mesma composição dos do conglomerado ora dispersos de modo caótico, ora mais organizados, representando o início da construção de um sistema fluvial anastomosado pouco desenvolvido.

A fácies de leque distal ocorre de modo restrito na área mais litorânea da porção norte (estrada para Gaibu) e sul (Serinhaém), constituída por arcósios conglomeráticos, estruturados sob a forma de camadas lateralmente contínuas, com espessuras de $1,50 \mathrm{~m}$, intercalados a argilitos micáceos vermelhos a verdes, com espessura máxima de $1 \mathrm{~m}$.

Esse pacote, cuja espessura total é de aproximadamente $11 \mathrm{~m}$, representa o avanço das partes mais distais do leque sobre o conglomerado proximal e é recoberto por outro pacote conglomerático do tipo sustentado pela matriz, apresentando blocos de menor calibre (Foto 3 ). 


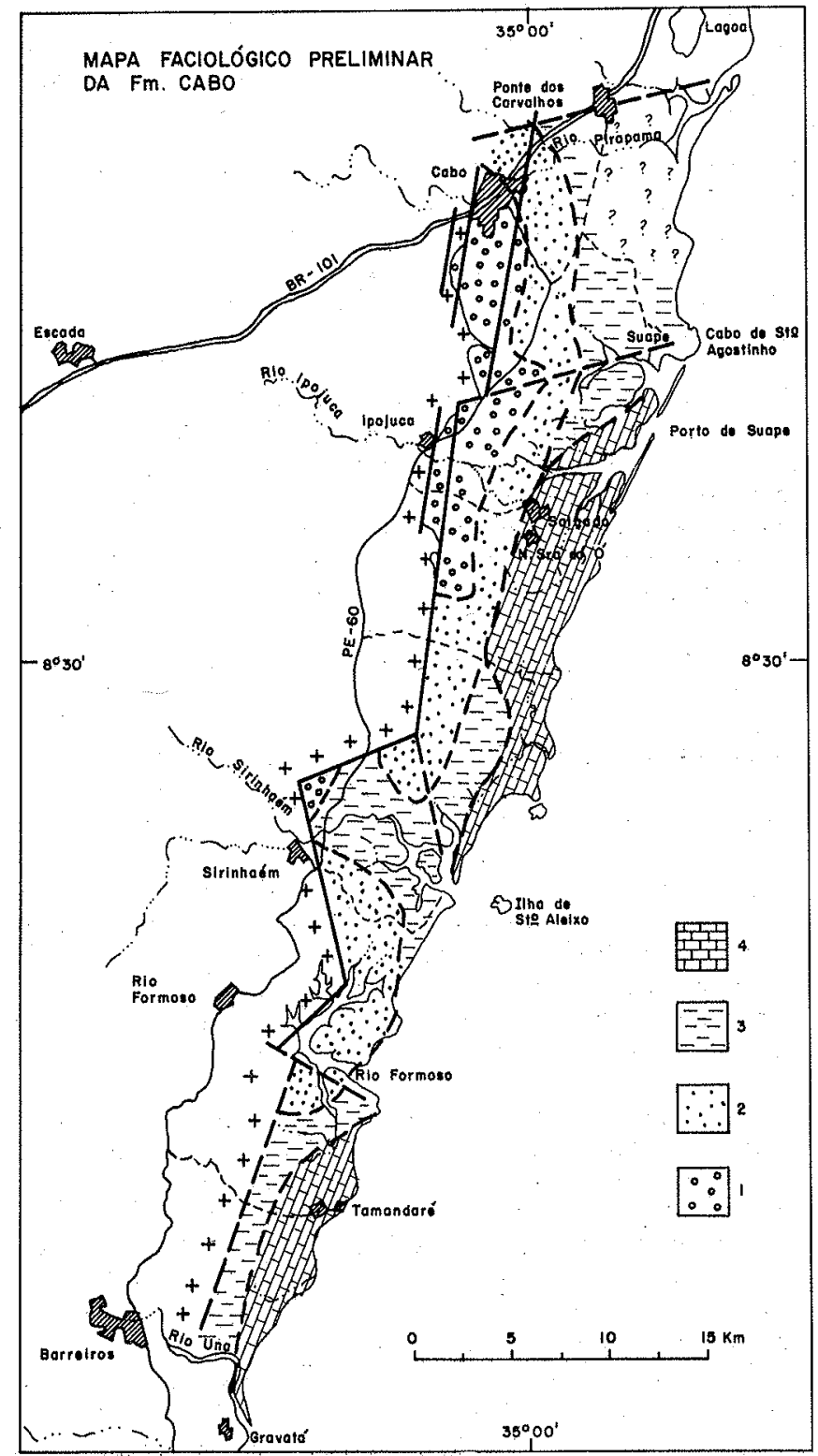

Figura 2 - Mapa faciológico da Formaçăo Cabo: 1. fácies de leque aluvial proximal; 2. fácies mediana de leque aluvial $e$ fácies fluvial entrelaçada; 3. fácies distal de leque aluvial e fácies lacustre; 4. fácies carbonática da Formação Estiva

Figure 2 - Facies map of Cabo Formation: 1. proximal alluvial for facies; 2 - middle facies of alluvial fan and braided alluvial facies; 3 . distal facies of alluvial fon or lacustine facies; 4 carbonatic facies of Estiva Formation.

A passagem de cada nível de arcósio conglomerático para o argiloso imediatamente acima se dá gradualmente em ambiente aquoso, caracterizando um ciclo de enxurrada que termina com o afogamento dos arcósios em um lago téctônico e a subseqüente deposição dos finos.

A passagem dos finos para o próximo nível de arcósio se dá de forma brusca, caracterizando um novo ciclo que se inicia com o aporte de clásticos mais grossos e se encerra pelo afogamento, com o meio perdendo energia e a argila avançando em direção à fonte.

Atribuídos a sucessivas enxurradas, esses ciclos estão intimamente associados à geração de fortes gradientes a partir de sucessivos pulsos tectônicos.

SISTEMA FLUVIAL ENTRELAÇADO Este sistema é representado por arcósios grossos a médios com estratificação cruzada acanalada de médio porte, com sets em gradação normal, tendo na base raros seixos de rochas graníticas muito bem arredondados (Foto 4). A fácies descrita reflete um processo tracional por corrente fluvial de padrão entrelaçado sob regime de fluxo intermediário a superior com ausência total de sedimentos finos.

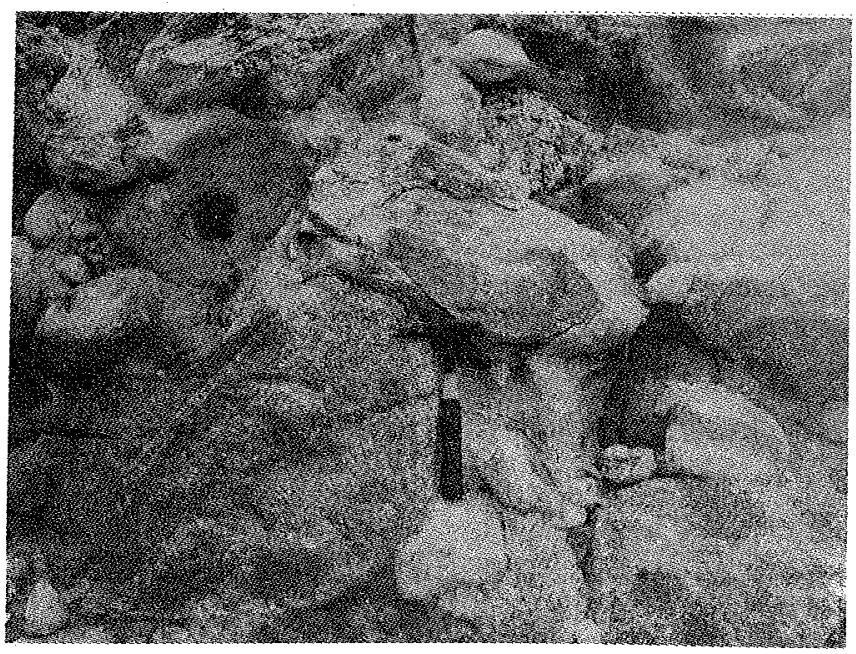

Foto I - Pseudomatriz gerada por esfoliaçào esferoidal em blocos do conglomerado Cabo.

Photo 1 - Pseudomatrix generated by espheroidal exfoliation in blocks of Cabo conglomerate

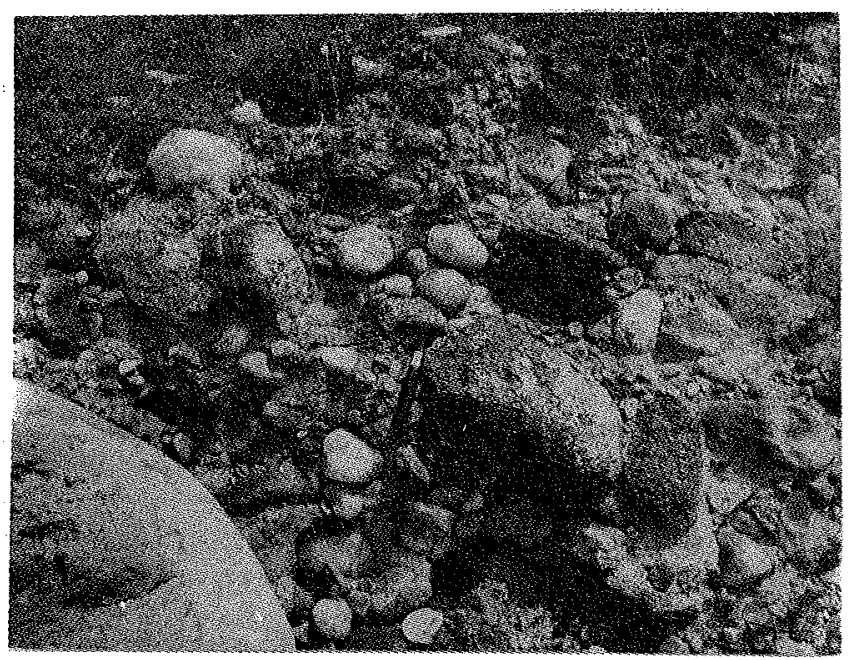

Foto 2 - Feição textural típica do conglomerado da Formaçáo Cabo

Photo 2-Typical textural feacture of the Cabo Formation conglomerate

Aflora expressivamente na porção norte da área em colinas de até $10 \mathrm{~m}$ de altura, expostos em cortes verticais. A fácil sustentação desses taludes deve-se à cimentação carbonática parcial freqüente nessa porção da área.

É comum sua alternância com a fácies mediana e até proximal do leque, em virtude da recorrência do processo de fluxos subaéreos, a cada novo pulso tectônico.

Uma fácies mais distal desse sistema pode ser observada em falésias na desembocadura do Rio Formoso e na praia de Guadalupe (município de Serinhaém). É representada por arcósios mais finos e mais bem selecionados, organizados sob regime de fluxo inferior, mostrando estratificações cruzadas acanaladas de pequeno porte. Algumas intercalações argilosas 
são localmente retrabalhadas e distribuídas como clastos na massa arcosiana.

SISTEMA LACUSTRE Essa fácies ocorre na porção sul da área restrita em superfície às imediações de Serinhaém (PE).

O afloramento é constituído por um folhelho com laminação plano-paralela, variegado (cores verde e castanho-avermelhada), fossilífero, que ocorria sob a forma

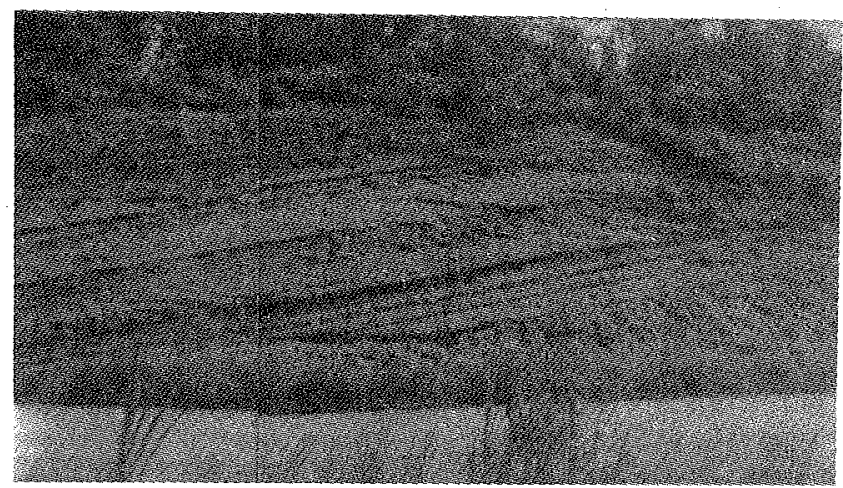

Foto 3 - Intercalação da fácies de leque aluvial distal, com os pelitos da fácies lacustre da Formação Cabo (Foto reproduzida de Pedrosa Jr. 1969)

Photo 3 - Intercalation of the distal alluvial for facies within the lacustine facies of Cabo formation (reproduced from Pedrosa Jr. 1969)

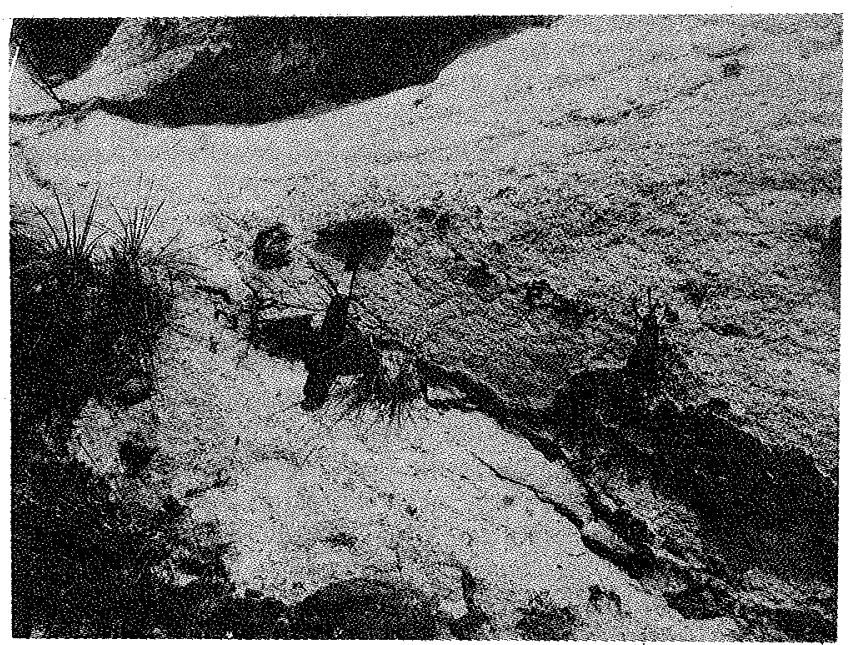

Foto 4 - Arcósio com estratificação cruzada da fácies fluvial entrelaçada da Formaçào Cabo

Phoio 4 - Cross bedded arkose of the braided alluvial facies of Cabo Formation

de um pequeno morro de menos de $5 \mathrm{~m}$ de altura, hoje totalmente arrasado em virtude do seu uso como matéria-prima para a Cerâmica Bom Jesus instalada em suas imediações.

O fóssil identificado neste afloramento foi o peixe de água doce Diplomystus longicostatus (Amaral \& Menor 1979), caracterizando um ambiente lacustre, para onde avançava a cunha de clásticos grossos das fácies de leque aluvial já apresentadas.

$O$ arranjo estrutural no trecho da área onde afloram as fácies distal e de lago sugere a existência de um gráben secundário onde as águas continentais poderiam ter sido acumuladas formando o citado lago.
O modelo deposicional adotado neste trabalho assemelha-se em muito ao que explica a sedimentação do Membro Carmópolis da Formação Muribeca, subordinada às mesmas condições tectônicas que a Formação Cabo. O perfil esquemático (Fig. 3) apresenta o desenvolvimento do sistema de leques aluviais e suas relações com as rochas vulcânicas.

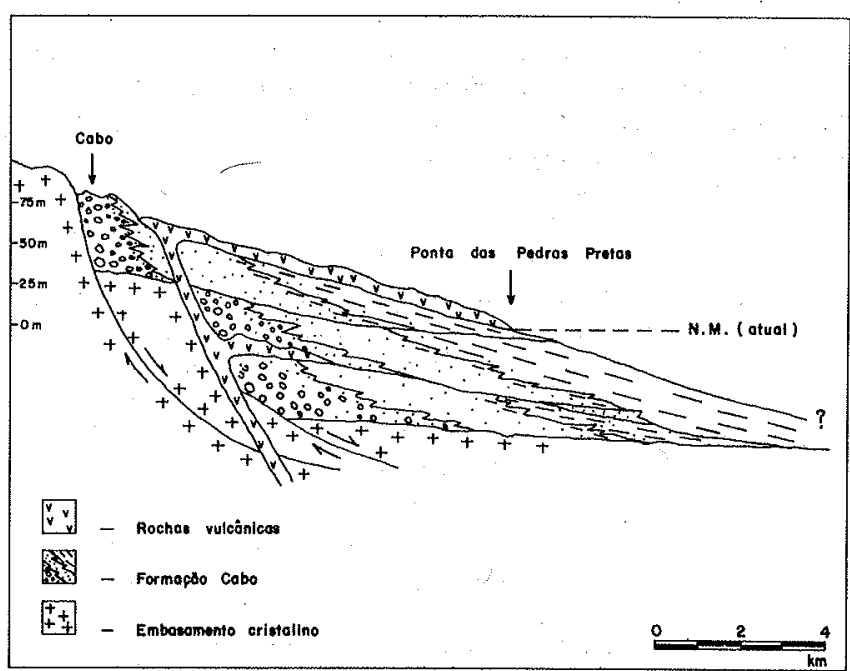

Figura 3 - Corte esquemático E-W da Formação Cabo mostrando seu condicionamento tectônico

Figure 3 - E-W Schematic profile of the Cabo Formation showing its tectonic framework

CONSIDERAÇÕES ESTRATIGRÁFICAS Os avanços no conhecimento da estratigrafia da faixa sedimentar costeira sul de Pernambuco nos últimos anos têm sido muito tímidos $\mathrm{em}$ virtude do desconhecimento de ocorrências economicamente interessantes, como se dá, por exemplo, a norte do Recife, onde foram encontrados calcários e fosfatos.

Os dados de subsuperfície disponíveis devem-se a poços para captação de água subterrânea e pesquisas geotécnicas, os quais nem sempre dispõem de descrições litológicas detalhadas e precisas, sendo ainda de limitada profundidade, auxiliando muito pouco no estudo estratigráfico.

De grande importância para esses estudos, é o poço estratigráfico 2-CPE-1-PE, perfurado pela Petrobrás em 1983 na praia do Cupe, $4 \mathrm{~km}$ a sudeste da localidade Nossa Senhora do Ó. Entretanto, como as análises geoquímicas não apresentaram boas perspectivas para a exploração de petróleo, só foram levados a efeito pela citada companhia os estudos preliminares de praxe. Apesar disso, o acesso ao material amostrado, ao perfil composto do poço e aos estudos paleontológicos preliminares, permitido pela Petrobrás, foi de grande valia para algumas correlações e extrapolaçốe: estratigráficas.

Nos trabalhos pioneiros sobre a Formação Cabo, as vagas referências quanto ao seu posicionamento estratigráfico e a aceitação de uma origem coluvial admitiam sua associação aos sedimentos cenozóicos do Grupo Barreiras (vide, por exemplo, Oliveira \& Leonardos 1943, Andrade \& Lins 1961).

Entretanto, as evidências de campo mostrando rochas vulcânicas cortando os conglomerados e afetando os calcários cretáceos já conhecidos permitiram a Kegel (1959) admitir idade entre Devoniano e Cretáceo para a Formação Cabo. Com base em dados semelhantes e em correlações com conglomerados sobrepostos à então imprecisa Série Alagoas (AL), Cobra (1960) admitiu idade neocretácea a eoterciária para a Formação Cabo, posicionando-a sobre os calcários de Ipojuca (Formação Estiva?), que foram aceitos como de idade albiana. 
As idades absolutas de 114 a 90 Ma obtidas por Vandoros et al. (1966) e Vandoros \& Valarelli (1976) para as rochas vulcânicas que cortam os conglomerados de Cabo e sua associação com o tectonismo formador da bacia (Asmus 1975, Ponte \& Asmus 1976, Asmus \& Carvalho 1978) situam de modo mais seguro a Formação Cabo entre o Eocretáceo (início do tectonismo) e o Turoniano (idade das vulcânicas mais jovens).

A presença do peixe fóssil Diplomystus longicostatus nos argilitos lacustres da Formação Cabo, datado como Neocomiano pelo Lamin (CPRM apud Amaral \& Menor 1979), colocaria os argilitos nesse intervalo não muito bem definido do Eocretáceo.

Entretanto, dados mais recentes, obtidos pelo estudo do poço 2-CPE-1-PE, situa o pacote clástico identificado como Formação Cabo no Andar Alagoas (Superior). O intervalo entre as profundidades de 432 e $2.832 \mathrm{~m}$ pertence à zona integrada P-270, seguida pela zona P-260 identificada até o limite perfurado de $2.593 \mathrm{~m}$ de profundidade, conforme o Sumário Biocronoestratigráfico fornecido pela Petrobrás.

Como a perfuração não atingiu o embasamento cristalino, interrompendo-se em pleno pacote clástico, não se pode determinar a idade limite inferior. Pelas correlações hoje bem aceitas da Formação Cabo com o Membro Carmópolis da Formação Muribeca, porém, pode-se admitir a possibilidade de encontrar idades pré-aptianas na base do pacote.

Quanto à idade neocomiana atribuída ao pacote de argilitos lacustres fossilíferos que ocorre a sul da área baseada na presença dos peixes fósseis, restam algumas dúvidas já que folhelhos também lacustres, com abundantes exemplares desse fóssil, ocorrem na área de Japaratinga (AL) dentro do pacote distal do Membro Carmópolis, associados a palinomorfos pertencentes à zona integrada P-270, incluída no Andar Alagoas (Superior)

Essa associação, indicando idade mais jovem para o peixe fóssil mencionado, redefine a posição dos argilitos; porém não impede a possibilidade já admitida de idades mais antigas na base da Formação Cabo.

$O$ reposicionamento dos argilitos fossiliferos é reforçado pelo fato de ocorrerem encaixados em pequenos grábens, sugerindo para os mesmos idade inferior ou no máximo equivalente à do pacote rudáceo lateralmente situado.

Para a definição do limite temporal superior da Formação Cabo são de grande importância as relações estratigráficas entre esta e a Formação Estiva, o que tem sido objeto de estudo desde que Oliveira \& Leonardos (1943) registraram a existência dos conglomerados na faixa costeira sul de Pernambuco.

Apesar de os calcários oferecerem melhor possibilidade de datação em virtude do seu conteúdo fossilífero, as ocorrências eram esparsas, de pequeno porte e foram sendo localizadas ao longo de quatro décadas.

Assim, Moraes (1928) correlacionou o calcário por ele identificado na Fazenda. Estiva com a Formação Maria Farinha, do Terciário, ao identificar gastrópodes semelhantes a Natica, sendo essa idade modificada para Turoniano por Maury (1930), que identificou várias espécies de gastrópode Actaeonella.

As ocorrências conhecidas a seguir resultaram do mapeamento de Cobra (1960), e de estudos feitos na área litorânea (Beurlen \& Cobra 1960), situadas respectivamente no Engenho Gameleira e nas proximidades de Tamandaré (PE). Em ambas, foi identificado o bivalve Neithea sergipensis, permitindo sua correlação com a Formação Riachuelo, de idade albiana, da Bacia Sergipe-Alagoas.

Posteriormente, outra ocorrência calcária é identificada por Maciel (1968) nas imediações de Cocaia e Outeiro Alto, apresentada vagamente como fossilífera (com macrofósseis e foraminíferos) e aceita como sincrônica à Formação Cabo.

No poço estratigráfico de Cupe, novas e interessantes informações foram acrescentadas. Entre elas, a de que ocorre na profundidade de $100 \mathrm{~m}$ um paleossolo desenvolvido no pacote clástico, marcando uma discordância sobre a qual ocorrem sedimentos clásticos com intercalações carbonáticas até a profundidade de $56 \mathrm{~m}$, onde se inicia um pacote calcário com $29 \mathrm{~m}$ de espessura, recoberto pelos sedimentos incoerentes de praia.

Os pacotes calcários aflorantes e subaflorantes têm sido comumente tratados nos trabalhos mais recentes como sendo correlatos e agrupados sob a denominação de Formação Estiva, sendo ora mencionada a idade turoniana de Maury (1930), ora a idade álbiana de Beurlen \& Cobra (1960).

Por outro lado, os níveis carbonáticos identificados apenas em subsuperfície quase sempre associados a arenitos, siltitos e folhelhos têm sido incluídos como parte integrante da Formação Cabo. Esses níveis ocorrem geralmente no intervalo entre 30 e $70 \mathrm{~m}$ de profundidade, como pôde ser observado na área do Projeto Suape (Amaral \& Menor 1979, Laurindo 1983).

Em amostras de calha do poço de Cupe, Lima (comunicação verbal em 1987) identificou pólens (associados a dinoflagelados e foraminíferos quitinosos) com idade rieocenomaniana/eoturoniana em folhelhos cinza calcíferos que ocorrem a $66 \mathrm{~m}$ de profundidade, à semelhança do que já observara em poços do Projeto Suape, em litologias e cotas equivalentes.

Essas conclusões são compatíveis com a correlação apresentada por Laurindo (1983) entre esses níveis carbonáticos e o Membro Ibura da Formação Muribeca, da Bacia Sergipe-Alagoas, que se baseou essencialmente nas características litológicas.

O caráter marinho deste material, evidenciado por seu conteúdo fóssil, está mais de acordo com a idéia de Amaral \& Menor (1979) de sucessivos ciclos transgressivos depositando carbonatos em um ambiente que evoluiu de continental a marinho. Entretanto, a idade cenomaniana/turoniana para esses níveis carbonáticos não permite sua correlação com a Formação Rio Pitanga (Neocomiano) ou Muribeca (Aptiano), como foi proposto no mesmo trabalho. Ao contrário, essa datação torna mais coerente sua inclusão na Formação Estiva, mesmo que esta denominação esteja tradicionalmente associada a calcários e não a outras litologias como folhelhos e arenitos calcíferos.

Novos dados paleontológicos resultantes da identificação do bivalve Lopha ramicola em amostras do calcário do Engenho Gameleira (Muniz comunicação verbal em 1987) podem apontar para uma idade pós-albiana para a Formação Estiva, à semelhança do que se verifica nos calcários turónianos da Formação Jandaíra da Bacia Potiguar.

Reunidas as informaçôes disponíveis, relacionadas ao posicionamento estratigráfico das formaçōes Cabo e Estiva, destacam-se como mais significativos, os seguintes fatos:

a) Todas as determinações paleontológicas até agora feitas no pacote clástico, do poço de Cupe, a partir da profundidade de $400 \mathrm{~m}$ até quase $3.000 \mathrm{~m}$, indicaram idade Neo-Alagoas (zonas integradas P-260 e P-270).

b) A existência de pelo menos um nível de paleossolo nesse pacote clástico, verificado nos testemunhos do poço de Cupe, ná profundidade aproximada de $100 \mathrm{~m}$.

c) A ocorrência de níveis carbonáticos intercalados em sedimentos clásticos no poço de Cupe e em diversos poços do Projeto Suape, principalmente entre as profundidades de 30 a $70 \mathrm{~m}$.

d) A determinação da idade neocenomaniana/eoturoniana com base em pólens, em folhelhos negros da área de Suape e folhelhos cinza do poço de Cupe em profundidades próximas de $60 \mathrm{~m}$.

e) A identificação da Lopha ramicola (associada ao Turoniano da Bacia Potiguar). no calcário do Engenho Gameleira e a aceitação até os dias atuais da idade turoniana 
para o calcário com Actaeonella da Fazenda Estiva.

Com base nesses fatos, pode ser proposta uma seqüência evolutiva na qual a Formação Cabo é representada por um pacote clástico, sintectônico, que foi desenvolvido na fase rifte durante a etapa final de abertura do Oceano Atlântico Sul. Este pacote clástico, sob condições de quiescência tectônica, ficou exposto por um tempo suficiente para o desenvolvimento de um paleossolo bastante oxidado, que marcaria uma clara discordância sobre a qual seria iniciada nova fase de sedimentação, provavelmente durante o Neocenomaniano a Eoturoniano.

A partir do avanço quase contínuo do nível do mar, o ambiente passaria de continental a marinho, refletindo-se pelo aumento gradativo da sedimentação carbonática intercalada aos clásticos continentais.

Esse pacote corresponderia à Formação Estiva, que seria então litologicamente redefinida a fim de abrigar, além dos calcários, os folhelhos e arenitos calcíferos. Essa hipótese reúne melhores condições de aceitação, tendo em vista a tradicional associação da Formação Cabo com termos litológicos clásticos e da Formação Estiva com termos carbonáticos (Fig. 4).

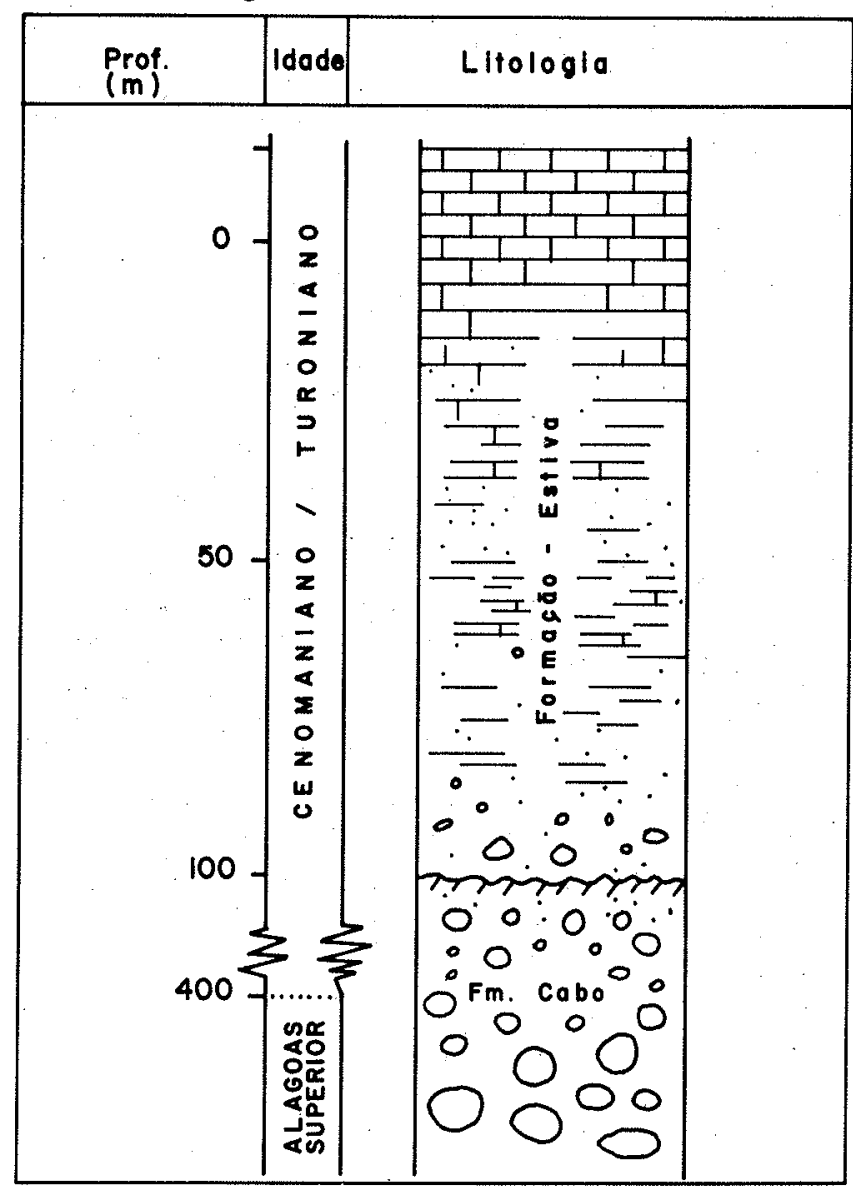

Figura 4 - Perfil colunar mostrando a passagem Formação Cabo/Formação Estiva

Figure 4 - Collumnar section showing the crossing from Cabo Formation to Estiva Formation

Permanece ainda indefinida, por falta de melhores informações, a comprovação de sedimentação albiana, apresentada por Beurlen \& Cobra (1960), com base em fragmentos ditos mal preservados de conchas fósseis. Desse modo acredita-se que, à luz dos dados mais recentes, tem maior sustentação a correlação estratigráfica da Formação Estiva com o intervalo transgressivo Cenomaniano/ Turoniano, que corresponde, na Bacia Sergipe-Alagoas às formaçōes Riachuelo (Membro Aguilhada) e Cotinguiba (Membro Sapucari).

As relações estratigráficas entre as unidades estudadas e as demais unidades que compõem o contexto regional da faixa sedimentar costeira Pernambuco/Paraíba são mostradas no quadro estratigráfico esquemático (Fig. 5).

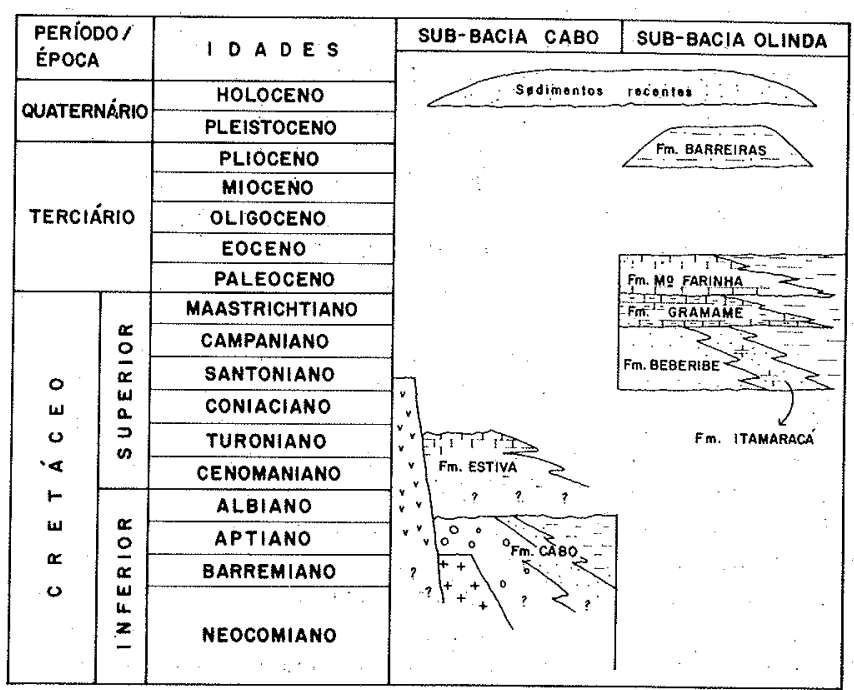

Figura 5 - Quadro estratigráfico esquemático para a Bacia Pernambuco-Paraiba, distinguindo as sub-bacias Cabo $e$ Olinda separadas pelo Lineamento Pernambuco

Figure 5 - Schematic stratigraphic chart of the Pernambuco - Caraiba Basin, distinguishing Cabo and Olinda sub-basins, on separed by the Permanbuco Lincarment

CONSIDERAÇÔES FINAIS Caracterização Litoestratigráfica A Formação Cabo representa uma unidade litotestratigráfica com identidade própria, distinta da Formação Estiva. $\hat{E}$ constituída por conglomerados polimíticos de diferentes diâmetros e graus de organização, por arcósios conglomeráticos ou não, apresentando cimentação carbonática parcial, e por siltitos, argilitos e folhelhos cinza a negros, localmente fossiliferos. A cimentação carbonática é o processo diagenético mais freqüente, sendo mascarado em superfície pelo intemperismo químico.

A Formação Estiva é constituída por uma seqüência clástico-carbonática depositada discordantemente sobre a Formação Cabo, iniciando-se na base com arcósios conglomeráticos ou não, intercalados a folhelhos cinza a pretos, com crescente participação carbonática, chegando, no topo da seção, a margas e calcários dolomíticos fossilíferos.

Em relação à Bacia Sergipe-Alagoas, as formações Cabo e Estiva correlacionam-se cronoestratigraficamente com o. Membro Carmópolis da Formação Muribeca e com o Membro Sapucari da Formação Cotinguiba, respectivamente.

Variações texturais Texturalmente imatura, tanto do ponto de vista físico como químico, a Formação Cabo apresenta um aspecto singular. Apesar da grande quantidade de feldspatos preservados, do caráter anguloso a subanguloso dos elementos na fração areia/grânulo e da proximidade da falha limitante do depósito, os seixos, calhaus e matacões que constituem o conglomerado são muito bem arredondados e, quando graníticos, com alta esfericidade. Esse arredondamento, que já ocorria no embasamento fraturado, antes da sedimentação, é cada vez mais acentuado pelo intenso processo de esfoliaçấo esferoidal que atinge toda a faixa costeira, produzindo uma falsa matriz in situ que se incorpora por pressão litostática à massa granular intersticial dos blocos. Idade Novos dados paleontológicos (datação por pólens) e 
estratigráficos (perfilagem do poço 2-CPE-1-PE) permitem situar a deposição da Formação Cabo no intervalo Alagoas Superior (zonas integradas P-260 e P-270).

Entretanto, como no poço estratigráfico citado não foi atingido o embasamento cristalino, deve-se admitir a possibilidade de idades mais antigas na base do pacote, até novas investigações nessas porções mais profundas.

Espessura A espessura da Formação Cabo é bastante variável tendo em vista o escalonamento de blocos que se verifica em seu substrato. Assim, é possível alcançar o embasamento cristalino com perfuraçöes de poucas dezenas de metros, como ocorre nas proximidades de São José da Coroa Grande (PE), ao mesmo tempo que o único poço profundo da área (2-CPE-1-PE), perfurado na praia de Cupe, alcançou $2.947 \mathrm{~m}$ de profundidade na Formação Cabo, sem atingir o embasamento.

A existência de espessuras superiores a $3.000 \mathrm{~m}$ para a Formação Cabo, equivalente àquelas encontradas na Bacia Sergipe-Alagoas, abre uma nova perspectiva para a retomada da pesquisa de hidrocarbonetos nessa área, principalmente em seu prolongamento na plataforma, dentro de uma faixa de direção NE-SW a partir de Suape, que corresponde ao gráben mais profundo da Sub-bacia Cabo.

Caracterização Tectono-Sedimentológica A Formação Cabo tem sua origem associada ao rifteamento sul-atlântico Eocretáceo a partir de uma sedimentação cíclica governada por pulsos tectônicos.

Sedimentologicamente, representa um sistema de leques aluviais coalescentes formando-se em ambiente continental ao pé de falésias de falhas normais de grandes rejeitos, progradando para um lago tectônico.

Sua construção sedimentológica é interrompida e imediatamente retomada em gradientes mais fortes, a cada reativação sucessiva, apresentando-se com geometria bastante complexa, dificultando o rastreamento em superfície de suas fácies proximal, mediana e distal.

Sobre esses leques desenvolve-se um sistema fluvial entrelaçado que evolui para $\mathrm{E}$ e SE, onde são encontradas as fácies mais distaiis.

O sistema lacustre aflora de modo restrito na porção sul da sub-bacia ocupando um pequeno gráben, que era periodicamente invadido por clásticos grossos dos leques aluviais progradantes.

Agradecimentos As autoras expressam seus agradecimentos à UFPE (Propesq) e à Finep (PADCT), pelo suporte financeiro; à Petrobrás (Cenpes), pelo acesso aos testemunhos do poço 2-CPE-1-PE, ao sumário biocronoestratigráfico e a seu perfil composto; aos professores Jannes M. Mabesoone (Sedimentologia, UFPE), Geraldo Barros da Costa Muniz (Paleontologia, UFPE) e Murilo Rodolfo de Lima (Palinologia, USP), pelas valiosas discussões em suas áreas de competência.

\section{REFERÊNCIAS BIBLIOGRÁFICAS}

ALVES, E.C. \& COSTA, M.P.A, 1986. Interpretação sismo-estratigráfica da porção norte do platô de Pernambuco e suas possíveis correlações com a Bacia Pernambuco-Paraíba. In CONGR. BRAS. GEOL., 34, Goiânia, 1986. Anais... Goiânia, SBG. v. 1, p. 286-297.

AMARAL, A.J.R. \& MENOR, E.A. 1979. A seqüência vulcano-sedimentar cretácea da tegião de Suape (PE): interpretação faciológica e considerações metalogenéticas. In SIMP. GEOL. NORDESTE, 9, Natal 1979. Anais... Natal, SBG/Núcleo NE. v.7, p. 251-269.

ANDRADE, G.O. \& LINS, R.C. 1961. O conglomerado do baixo Pirapama. Cadernos da Faculdade de Filosofia de Pernambuco.v. 2. Série VI-2, fasc. XX-1. Recife, 1961.21 p.

ASMUS, H.E. 1975. Controle estrutural da deposição mesozóica nas bacias da margem continental brasileira. Rev. Bras. Geoc., 5(3):160-175.

ASMUS, H.E. \& CARVAHO, J.C. 1978. Condicionamento tectônico da sedimentação nas bacias marginais do nordeste do Brasil (Sergipe/Alagoas e Pernambuco/Paraíba). In: Petrobrás. Aspectos estruturais da margem continental leste e sudeste do Brasil. Rio de Janeiro. Cenpes/Dintep. p. 7-24. (SÉrie Projeto REMAC 4).

BEURLEN, K. \& COBRA, R.Q. 1960 . Novas localidades fossilifera no litoral sul de Pernambuco. An. Acad. brasil. Ciênc. (Resumo das Comunicacōes) 32(2):VII.

BIGARELLA, J.J. \& ANDRADE, G.O. de. 1964. Considerações sobre a estratigrafia dos sedimentos cenozóicos em Pernambuco (Grupo Barreiras). Arquivos Inst, Ciênc. Terra, v. 2, p. 2-14.

COBRA, R.Q. 1960. Geologia da região do Cabo de Santo Agostinho. 70 p. (Tese de Doutoramento, Univ. Minas Gerais. Fac. Filos.), (inédita)

FALCÃO, M.F.L. 1976. Fácies conglomeráticas da Formaçâo Cabo. 96 p. (Dissertação de Mestrado, UFPE), (inédita)

FOLK, R.L. 1974. Petrology of sedimentary racks. Austrin, Hemphill Publishing Co., $182 \mathrm{p}$.

KEGEL, W. 1959. O conglomerado de Cabo. Arquivos de Geologia., Universidade do Recife, 1:23-25.

LAURINDO, A.M.O. 1983. Estudo faciologico dos carbonatos da Formação Cabo-Pernambuco. 91 p. (Dissertação de Mestrado, UFPE), (inédita)
MABESOONE, J.M. 1971. O conglomerado da Formação Cabo: origem múltipla? Rev. da Associação dos Geólogos de Pernambuco, Recife, 1(3): 25-32.

MACIEL, E.A. 1968. Contribuiçấo à geologia geral de Ipojuca-PE. 57 p. (Relatório de graduação. Escola de Geologia da UFPE) (inédito)

MAURY, C.J. 1930. O Cretáceo da Parahyba do norte. Serv. Geol. Mineral. do Brasil., Monograph. VIII, Rio de Janeiro, p. 251-266.

MORAES, L.J. 1928. Estudos geológicos no Ėstado de Pernambuco. Boletim do Serviço Geologico e Mineralógico do Brasil, Rio de Janeiro, $\theta$ 28, 32:69-70.

OLIVEIRA, A.I. \& LEONARDOS, O.H. 1943. Geologia do Brasil. 2a ed. Serviço de Inf. Agrícola. Rio de Janeiro, p. 551, 662-663.

PEDROSA Ir., I. 1969. Geologia e geofísica da área Serinhaém-Rio Formoso, PE. 103 p. (Relatório de graduação, Escola de Geologia da UFPE), (inédito)

PONTE, F.C. \& ASMUS, H.E 1976. The Brazilian marginal basins: current state of knowledge. An. Acad. bras. Ciênc., 48(supl.):215-39. Simpósio Internacional sobre as margens continentais do tipo Atlântico.

RAND, H.M. 1976. Estudos geofísicos na faixa litorânea ao sul do Recife. 112 p. (Tese de concurso para livre docente, UFPE), (inédita)

VANDOROS; P.; CORDANI, U.; MATZKO, J.J. 1966. Idades absolutas das rochas ígneas da região do Cabo, Pernambuco. In: CONGR. BRAS. GEOL., 20, Vitória. 1966. Resumo das Comun... Vitória, SBG. v. 1, p. 64-66.

VANDOROS, P.\& VALARRELLI, J.V. 1976. Geologia da regiấo do Cabo de Santo-Agostinho-PE. In: CONGR. BRAS. GEOL., 29, Ouro Preto. 1976. Res. Com. Ouro Preto, SBG. p. 19.

MANUSCRITO 536 Recebido em 09 de maio de 1988 Revisão recebida em 05 de outubro de 1988 Revisáo aceita em 13 de outubro de 1988 